\title{
A Food Poisoning Outbreak in Al-Khazir U2 Camp of Internally Displaced Persons - Iraq, Summer 2017
}

\author{
Kamal Kadhim; K Fathallah; Al Jaafar; A Hamad; S Saadoon; Z Awad; F Lami
}

\section{Corresponding Author:}

Kamal Kadhim

\section{Abstract}

Background: Globally, about 600 million fall ill and 420,000 die every year after eating contaminated food. On June 12, 2017, Iraq CDC informed about a food poisoning outbreak among internally displaced persons (IDPs) in Al-Khazir camp, Northern Iraq after consuming "Iftar" (Ramadan breakfast) provided by an NGO. "Iftar" was composed of rice, white bean broth, chicken, yogurt, date and bread.

Objective: The objective was to describe the outbreak, identify the causative agent and recommend preventive measures.

Methods: A team of FETP residents dispatched to investigate the outbreak. The case patient was defined as any person in the camp who ate "Iftar" and developed nausea/vomiting or diarrhea or abdominal pain. A retrospective cohort study was initiated.

Results:

Conclusions: The large number of ordered meals from a single restaurant led to suboptimal food preparation and storage. We recommended rigorous implementation of food handing instructions and health education of the food handlers.

(iproc 2018;4(1):e10573) doi: $10.2196 / 10573$

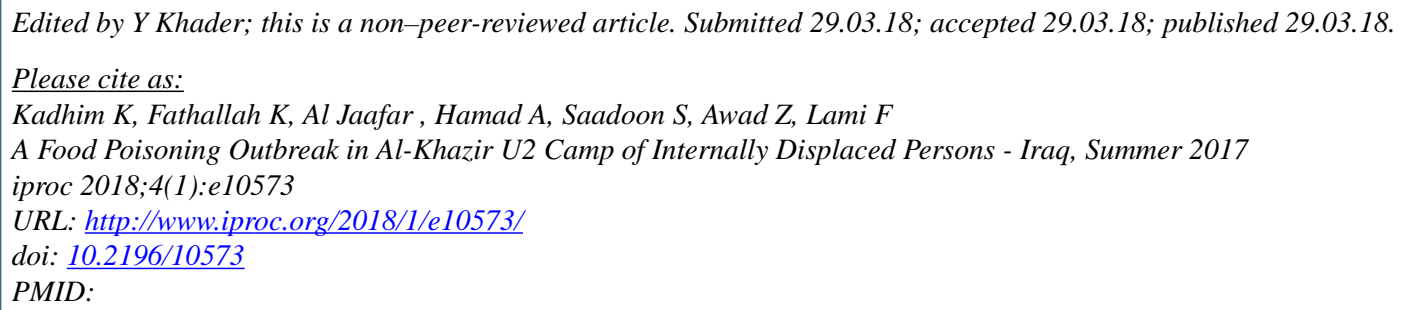

CPresenter: Dr. Kamal Kadhim, K Fathallah, Al Jaafar, A Hamad, S Saadoon, Z Awad, F Lami. Originally published in Iproceedings (http://www.iproc.org), 29.03.2018. This is an open-access article distributed under the terms of the Creative Commons Attribution License (https://creativecommons.org/licenses/by/4.0/), which permits unrestricted use, distribution, and reproduction in any medium, provided the original work, first published in Iproceedings, is properly cited. The complete bibliographic information, a link to the original publication on http://www.iproc.org/, as well as this copyright and license information must be included. 